Toshio Itoh • Kenjiro Kikuchi • Yasuhisa Odagawa

Shigeo Takata $\cdot$ Katsusuke Yano $\cdot$ Shintaro Okada

Noriyuki Haneda $\cdot$ Satoshi Ogawa • Osami Nakano

Yosuke Kawahara · Hideaki Kasai • Toshio Nakayama

Tatsuya Fukutomi · Harumizu Sakurada

Akihiko Shimizu • Yoshio Yazaki • Ryozo Nagai

Yusuke Nakamura $\cdot$ Toshihiro Tanaka

\title{
Correlation of genetic etiology with response to $\beta$-adrenergic blockade among symptomatic patients with familial long-QT syndrome
}

Received: September 29, 2000 / Accepted: October 12, 2000

\begin{abstract}
Mutations in any of the five genes $K C N Q 1$, $K C N H 2, K C N E 1, K C N E 2$, and SCN5A can be responsible for familial long QT syndrome (LQTS), an arrhythmogenic disorder that entails a high risk of sudden death. $\beta$-Adrenergic blocking agents are the first therapeutic choice, and $80 \%$ of patients treated with these agents show symptomatic relief; however the remaining $20 \%$ do not respond well. We previously performed a nationwide analysis of familial long QT syndrome (LQTS) in Japan and identified 32 mutations in the $K C N Q 1$ and $K C N H 2$ genes. In the present retrospective study, we found that patients carrying mutations in the $K C N Q 1$ gene responded better to $\beta$-adrenergic blocking
\end{abstract}

T. Itoh $\cdot$ Y. Nakamura $\cdot$ T. Tanaka $(\bowtie)$

Laboratory of Molecular Medicine, Human Genome Center,

Institute of Medical Science, University of Tokyo, 4-6-1

Shirokanedai, Minato-ku, Tokyo 108-8639, Japan

Tel. +81-3-5449-5374; Fax +81-35449-5406

e-mail: toshitan@ims.u-tokyo.ac.jp

T. Itoh $\cdot$ R. Nagai

Second Department of Internal Medicine, Gunma University School of Medicine, Maebashi, Japan

\section{K. Kikuchi}

First Department of Internal Medicine, Asahikawa Medical College, Asahikawa, Japan

Y. Odagawa

Department of Pediatrics, Hokkaido University School of Medicine, Sapporo, Japan

S. Takata

First Department of Internal Medicine, School of Medicine,

Kanazawa University, Kanazawa, Japan

K. Yano

Third Department of Internal Medicine, School of Medicine,

Nagasaki University, Nagasaki, Japan

S. Okada

Department of Pediatrics, Osaka University Medical School, Osaka, Japan

N. Haneda

Department of Pediatrics, Shimane Medical University, Izumo, Japan

S. Ogawa

Department of Internal Medicine, Keio University School of

Medicine, Tokyo, Japan agents than those with $K C N H 2$ mutations (12 of 13 vs 1 of $5 ; P=0.0077$, Fisher's exact test). This is a good example of the power of genetic diagnosis to direct the selection of appropriate therapy for patients with diseases of heterogeneous genetic etiology.

Key words Long QT syndrome - Genotype/phenotype correlation $\cdot \beta$-blocker $\cdot$ Arrhythmia $\cdot$ Genetic heterogeneity

\section{Introduction}

Familial long QT syndrome (LQTS) is an autosomal dominant arrhythmogenic disorder carrying a high risk of syncope and sudden death. In recent years, five responsible genes $(K C N Q 1, K C N H 2, K C N E 1, K C N E 2$, and SCN5A;

O. Nakano

Department of Pediatrics, Takamatsu Municipal Hospital, Takamatsu, Japan

Y. Kawahara

Division of Cardiology, Department of Medicine, Kawasaki Medical School, Kurashiki, Japan

H. Kasai

Department of Cardiology, Metropolitan Kiyose Children's Hospital, Tokyo, Japan

T. Nakayama

Department of Internal Medicine, Nakayama Clinic, Utsunomiya, Japan

T. Fukutomi

Department of Internal Medicine, Bisai City Hospital, Bisai, Japan

H. Sakurada

Division of Cardiology, Metropolitan Hiroo Hospital, Tokyo, Japan

A. Shimizu

Second Department of Internal Medicine, Yamaguchi University School of Medicine, Ube, Japan

Y. Yazaki

International Medical Center of Japan, Tokyo, Japan

R. Nagai

Department of Cardiovascular Medicine, University of Tokyo

Graduate School of Medicine, Tokyo, Japan 
Wang et al. 1996; Curran et al. 1995; Splawski et al. 1997; Schulze-Bahr et al. 1997; Abbott et al. 1999; Wang et al. 1995) have been identified; four of them encode cardiac potassium channels, and the fifth $(S C N 5 A)$ encodes sodium channels. Although another genetic locus has also been identified on chromosome 4 (Schott et al. 1995), the gene responsible has not yet been found. According to previous reports, including ours (for review, see "The long QT syndrome database" home page, under approval of Human Genome Organisation (HUGO); http://www.ssi.dk/ en/forskning/lqtsdb/lqtsdb.htm), KCNQ1 and $K C N H 2$ represent about half and about $40 \%$, respectively, of the total mutations found in LQTS. The three other genes seem to play a relatively less important role in the pathogenesis of LQTS. In a previous nation-wide analysis of familial LQTS, we ascertained 114 LQTS families throughout Japan, obtaining their informed consent for genetic analysis. In the process of mutational analyses for the five genes noted above, we identified 32 different mutations, 16 in the $K C N Q 1$ gene and 16 in $K C N H 2$ (Tanaka et al. 1997; Itoh et al. 1998a; Itoh et al. 1998b; our unpublished data) in our population sample; we found no mutations in any other of the genes associated with LQTS.

As a preventive measure, $\beta$-adrenergic blockade is generally the first therapeutic choice; about $80 \%$ of LQTS patients show symptomatic relief with drug treatment (Locati and Schwartz 1992). However, the remaining $20 \%$ show poor response to $\beta$-blockers and require more intensive therapy, such as the implantation of an automatic internal cardioverter-defibrillator (AICD). The variability of QT intervals and clinical signs among carriers of the genes responsible for LQTS makes accurate diagnosis difficult (Vincent et al. 1992), but early diagnosis and preventive therapy is crucial for protecting these patients from sudden cardiac death. Hence, if the different responses to $\beta$ - blockers reflect mutations at different sites within a given gene, or mutations in different genes, genetic diagnosis might provide information to govern the choice of an appropriate therapeutic approach.

In an effort to clarify a possible genotype/phenotype relationship, we retrospectively looked for a correlation between genetic etiology and response to drug treatment. Here we describe the one which should be of use in the choice of therapy.

\section{Patients and methods}

\section{Selection of patients}

To search for a genotype/phenotype relationship, we first selected LQTS patients who had been identified in our previous studies and in our unpublished data as carriers of mutations in the genes responsible (Tanaka et al. 1997; Itoh et al. 1998a; Itoh et al. 1998b). Then, we chose patients with histories of syncope who had received simple $\beta$-adrenergic blockade therapy, to investigate the effectiveness of this therapy. Those patients who showed no episodes of syncope throughout the follow-up period, after taking a $\beta$-blocker were considered responders. As described in our previous reports, all patients gave their informed consent before they were enrolled in this study.

\section{Statistical analysis}

Statistical analysis was performed using Fisher's exact test. $P$ values under 0.05 were considered significant.

Table 1. Effect of simple $\beta$-adrenergic blockade therapy on symptomatic LQTS patients

\begin{tabular}{|c|c|c|c|c|c|c|c|}
\hline Mutated gene & Patient $^{\mathrm{a}}$ & Sex & $\begin{array}{l}\text { Age } \\
\text { (years) }\end{array}$ & QTc (ms) & Drug & $\begin{array}{l}\text { Symptom after } \\
\text { therapy }\end{array}$ & $\begin{array}{l}\text { Follow-up } \\
\text { period (years) }\end{array}$ \\
\hline$K C N Q 1$ & 3817 & $\mathrm{~F}$ & 43 & 660 & Propranolol & - & 16 \\
\hline$K C N Q 1$ & $100-1$ & M & 8 & 620 & Atenolol & - & 1 \\
\hline$K C N Q 1$ & $100-2$ & $\mathrm{~F}$ & 38 & 650 & Atenolol & - & 1 \\
\hline$K C N Q 1$ & 5604 & $\mathrm{~F}$ & 21 & 590 & Atenolol & - & 5 \\
\hline$K C N Q 1$ & 3612 & $\mathrm{~F}$ & 26 & 530 & Propranolol & - & 8 \\
\hline$K C N Q 1$ & 2905 & M & 14 & 510 & Propranolol & - & 7 \\
\hline$K C N Q 1$ & 6114 & $\mathrm{~F}$ & 22 & 570 & Propranolol & - & 14 \\
\hline$K C N Q 1$ & 6115 & $\mathrm{~F}$ & 20 & 550 & Propranolol & - & 14 \\
\hline$K C N Q 1$ & 6117 & $\mathrm{~F}$ & 17 & 550 & Propranolol & - & 6 \\
\hline$K C N Q 1$ & 1004 & $\mathrm{~F}$ & 25 & 505 & Propranolol & - & 7 \\
\hline$K C N Q 1$ & 1911 & M & 15 & 480 & Bisoprolol & - & 3 \\
\hline$K C N Q 1$ & 30 & M & 18 & 490 & Propranolol & - & 4 \\
\hline$K C N Q 1$ & 2515 & $\mathrm{~F}$ & 21 & 530 & Propranolol & Syncope & - \\
\hline $\mathrm{KCNH} 2$ & 6801 & $\mathrm{~F}$ & 65 & 520 & Propranolol & - & 8 \\
\hline $\mathrm{KCNH} 2$ & 2009 & M & 25 & 500 & Propranolol & Syncope & - \\
\hline $\mathrm{KCNH} 2$ & 2211 & $\mathrm{~F}$ & 24 & 550 & Propranolol & Syncope & - \\
\hline $\mathrm{KCNH} 2$ & 8001 & M & 21 & 700 & Propranolol & Syncope & - \\
\hline $\mathrm{KCNH} 2$ & 101 & $\mathrm{~F}$ & 19 & 500 & Carteolol & Syncope & - \\
\hline
\end{tabular}

QTc, corrected QT interval

${ }^{a}$ Patient numbers refer to those in the study by Tanaka et al. (1997), Itoh et al. (1998a), and Itoh et al. (1998b) 


\section{Results and discussion}

We chose patients with histories of syncope who had received simple $\beta$-adrenergic blockade therapy. Among the 18 selected patients (listed in Table 1), 13 carried mutant KCNQ1 alleles (mean age, $22 \pm 10$ years; mean QTc, $556 \pm$ $59 \mathrm{~ms}$ ) and 5 had mutations in KCNH2 (mean age, $31 \pm 19$ years; mean QTc, $554 \pm 84 \mathrm{~ms}$ ). Their medical records were examined in detail; drug therapy was considered to have been effective when there had been no episodes of syncope throughout the follow-up period ( $7.2 \pm 4.8$ years). Simple $\beta$ adrenergic blockade therapy seemed to have been effective for all but 1 of the symptomatic patients with mutated $K C N Q 1$ genes; in contrast, only 1 of the 5 patients carrying a mutated $\mathrm{KCNH} 2$ allele showed good response to drugs $(P=0.0077$; Fisher's exact test $)$.

The results of this genetic analysis imply that symptomatic patients with $\mathrm{KCNH} 2$ mutations should be cared for more intensively, i.e., they are candidates for AICDs. Because the functional property of the KCNQ1 channel is almost identical to that of Iks (Barhanin et al. 1996; Sanguinetti et al. 1996), with a dominant $\mathrm{K}^{+}$current in conditions of high sympathetic activity, mutant $K C N Q 1$ alleles may lead to inadequacy of action potential, which would shorten under adrenergic stress. By reducing this stress, $\beta$-adrenergic blockade therapy may protect carriers of $K C N Q 1$ mutations against syncope.

The evidence reported here provides a good example of the power of genetic diagnosis to direct the selection of appropriate therapy for patients with diseases of heterogeneous genetic etiology.

Acknowledgments We are indebted to all the LQTS patients and their family members who participated in this study. The work was supported in part by a Grant-in-Aid from the Ministry of Education, Science, Sports, and Culture of Japan.

\section{References}

Abbott GW, Sesti F, Splawski I, Buck ME, Lehmann MH, Timothy KW, Keating MT, Goldstein SA (1999) MiRP1 forms IKr potassium channels with HERG and is associated with cardiac arrhythmia. Cell 97:175-187

Barhanin J, Lesage F, Guillemare E, Fink M, Lazdunski M, Romey G (1996) KvLQT1 and IsK (minK) proteins associate to form the IKs cardiac potassium current. Nature 384:78-80

Curran ME, Splawski I, Timothy KW, Vincent GM, Green ED, Keating MT (1995) A molecular basis for cardiac arrhythmia: HERG mutations cause long QT syndrome. Cell 80:795-803

Itoh T, Tanaka T, Nagai R, Kamiya T, Sawayama T, Nakayama T, Tomoike H, Sakurada H, Yazaki Y, Nakamura Y (1998a) Genomic organization and mutational analysis of $H E R G$, a gene responsible for familial long QT syndrome. Hum Genet 102:435-439

Itoh T, Tanaka T, Nagai R, Kikuchi K, Ogawa S, Okada S, Yamagata S, Yano K, Yazaki Y, Nakamura Y (1998b) Genomic organization and mutational analysis of $K V L Q T 1$, a gene responsible for familial long QT syndrome. Hum Genet 103:290-294

Locati EH, Schwartz PJ (1992) The idiopathic long QT syndrome: therapeutic management. PACE Pacing Clin Electrophysiol 15:1374-1379

Sanguinetti MC, Curran ME, Zou A, Shen J, Spector PS, Atkinson DL, Keating MT (1996) Coassembly of KvLQT1 and minK (IsK) proteins to form cardiac IKs potassium channel. Nature 384:80-83

Schott JJ, Charpentier F, Peltier S, Foley P, Drouin E, Bouhour JB, Donnelly P, Vergnaud G, Bachner L, Moisan JP, Marec HL, Pascal O (1995) Mapping of a gene for long QT syndrome to chromosome 4q25-27. Am J Hum Genet 57:1114-1122

Schulze-Bahr E, Wang Q, Wedekind H, Haverkamp W, Chen Q, Sun Y, Rubie C, Hordt M, Towbin JA, Borggrefe M, Assmann G, Qu X, Somberg JC, Breithardt G, Oberti C, Funke H (1997) KCNE1 mutations cause jervell and Lange-Nielsen syndrome. Nat Genet 17:267268

Splawski I, Tristani-Firouzi M, Lehmann MH, Sanguinetti MC, Keating MT (1997) Mutations in the hminK gene cause long QT syndrome and suppress IKs function. Nat Genet 17:338-340

Tanaka T, Nagai R, Tomoike H, Takata S, Yano K, Yabuta K, Haneda N, Nakano O, Shibata A, Sawayama T, Kasai H, Yazaki Y, Nakamura Y (1997) Four novel KVLQT1 and four novel HERG mutations in familial long QT syndrome. Circulation 95:565-567

Vincent GM, Timothy KW, Leppert M, Keating M (1992) The spectrum of symptoms and QT intervals in carriers of the gene for the long-QT syndrome. N Engl J Med 327:846-852

Wang Q, Shen J, Splawski I, Atkinson D, Li Z, Robinson JL, Moss AJ, Towbin JA, Keating MT (1995) SCN5A mutations associated with an inherited cardiac arrhythmia, long QT syndrome. Cell 80:805811

Wang Q, Curran ME, Splawski I, Burn TC, Millholland JM, VanRaay TJ, Shen J, Timothy KW, Vincent GM, de Jager T, Schwartz PJ, Towbin JA, Moss AJ, Atkinson DL, Landes GM, Connors TD, Keating MT (1996) Positional cloning of a novel potassium channel gene: KVLQT1 mutations cause cardiac arrhythmias. Nat Genet 12:17-23 